\title{
RESTORATION OF POST ENDODONTIC TREATMENT WITH FIBER-RESIN REINFORCED POST CORE SYSTEM
}

\author{
(RESTORASI PASCA PERAWATAN ENDODONTI DENGAN PASAK DAN INTI \\ YANG DIPERKUAT PITA FIBER RESIN)
}

\author{
Wandania Farahanny \\ Departemen Ilmu Konservasi Gigi \\ Fakultas Kedokteran Gigi, Universitas Sumatera Utara \\ Jl.Alumni No. 2 Kampus USU. Medan 20155 \\ Email:wandadrg@yahoo.com
}

\begin{abstract}
Final restoration of post endodontic treatment often uses substantial build up with post core foundation materials to retain a complete crown. Various post core materials and design have been introduced. Recently, the use of fiber-reinforced ribbon material which is made from ultra high polyethylene fiber system is becoming popular. It does not require the enlargement of the root canal space then the risk of root perforation may be eliminated. This material offers structural reinforcement to the teeth that will be restored. This case report discuss about the treatment of two patients, 28 and 19 year-old males who had crown fracture maxillary incisors and needed aesthetic restoration immediately. After endodontic treatment, a polyethylene fiber was used as fiber-reinforced post core with adhesive dual cure luting cement to conserve the remaining tooth structure. Direct micro hybrid resin composite was applied to create veneering of final restoration. In conclusion, the use of ribbon allows the clinician to make a translucent post core, an aesthetic direct composite restoration and structural reinforcement post core in one visit that does not need any laboratory procedure.
\end{abstract}

Key words: post endodontic treatment, fiber-reinforced ribbon, post core

\begin{abstract}
Abstrak
Restorasi akhir pada gigi setelah perawatan endodonti sering menggunakan pasak dan inti sebagai fondasi penahan mahkota penuh. Saat ini penggunaan pita fiber resin reinforced yang terbuat dari bahan ultra high polyethylene fiber sebagai pasak menjadi popular. Resiko terjadinya fraktur akar dapat berkurang karena sistem pasak ini tidak memerlukan perluasan saluran akar lebih banyak. Retensi pasak ini didapat dari sistem adhesif sehingga dapat menambah kekuatan struktural dari gigi yang akan direstorasi. Laporan kasus ini membahas perawatan yang dilakukan pada dua orang pasien yang mengalami fraktur mahkota pada gigi insisivus maksila dan membutuhkan segera restorasi estetis. Laki-laki berusia 28 dan 19 tahun. Setelah perawatan endodonti dilakukan, bahan polyethylene fiber digunakan sebagai pasak-inti dengan menggunakan semen luting resin untuk mempertahankan struktur gigi tersisa. Komposit resin micro hybrid diaplikasikan sebagai restorasi veneer untuk membentuk restorasi akhir. Sebagai kesimpulan, bahan polyethylene fiber reinforced dapat membuat restorasi estetis dan memperkuat pasak dan inti secara struktural dalam satu kali kunjungan tanpa harus melalui proses laboratorium.
\end{abstract}

Kata kunci: pasta peraswat endodonti, fiber resin reinforced, pasak

\section{PENDAHULUAN}

Restorasi akhir dengan menggunakan pasak sering dibutuhkan pada gigi yang telah dirawat endodonti. Pasak yang berada di dalam saluran akar berfungsi menjadi fondasi restorasi akhir, sedangkan inti berfungsi meningkatkan kekuatan dan retensi mahkota. Pemakaian pasak diindikasikan jika struktur gigi yang tersisa tidak memadai untuk mendukung res- torasi akhir. Fraktur mahkota yang terjadi akibat trauma adalah salah satu contoh kasus traumatik endodonti yang sering membutuhkan retensi pasak pada restorasi akhirnya.'

Selama ini pasak yang sering digunakan adalah pasak metal tuang (cast metal post) dan pasak metal buatan pabrik (fabricated metal post). Retensi pasak metal ini diperoleh dari sementasi bahan luting ke dalam saluran akar. Sistem pasak ini sering me- 
nimbulkan pergeseran antara pasak dan struktur gigi, karena hanya mengandalkan retensi mekanis dari semen luting. ${ }^{2}$ Penggunaan pasak metal tuang maupun pasak metal buatan pabrik membutuhkan pembuangan undercut lebih banyak untuk mempermudah pasak masuk dan beradaptasi dengan dinding saluran akar. Diameter ruang pasak semakin besar karena sebelumnya saluran akar sudah dilakukan preparasi saluran akar selama perawatan endodonti. Akibat pelebaran tersebut struktur gigi yang tertinggal menjadi lemah dan ketebalan dentin dinding saluran akar yang tersisa menjadi berkurang, sehingga restorasi yang menggunakan pasak metal tuang maupun pasak metal buatan pabrik cenderung rentan mengalami fraktur akar horizontal dan vertikal. ${ }^{2,3}$ Insidens terjadinya fraktur akar pada pasak metal tuang lebih tinggi dibandingkan pasak fiber karena pasak metal memiliki modulus elastisitas yang lebih besar daripada dentin. Estetis pasak metal mempunyai kelemahan karena sering menimbulkan bayangan abu-abu (gray zone) pada tepi servikal dentin radikular karena terjadinya korosi. ${ }^{4}$

Akhir-akhir ini telah dikembangkan suatu bahan pasak yang lebih estetis yaitu pasak fiber fabricated dan pasak customized dari pita fiber yang mengandalkan teknologi sistem adhesif untuk retensinya. Pasak fiber memiliki modulus elastisitas yang menyerupai modulus elastisitas dentin dan dapat berikatan kuat dengan struktur gigi menggunakan sistem adhesif. Pasak fiber dapat mengurangi insidens terjadinya fraktur akar pada restorasi yang tidak dapat diperbaiki. Oleh karena itu, penggunaan pasak fiber mulai banyak diminati. ${ }^{2,3,5}$

Pasak fiber customized berbentuk pita yang terbuat dari bahan polyethylene fiber sebagai salah satu material yang populer pada saat ini, memiliki banyak kegunaan dan kelebihan pada pemakaiannya. Selain memperkuat struktur gigi, sistem pasak ini retentif, estetis, dan dapat dibentuk sesuai dengan bentuk saluran akar. Sistem pasak pita ini menggunakan anatomi internal saluran akar, area permukaan sehingga bentuk pasak yang menyatu dengan semen luting adhesif akan menghasilkan kontak rapat mengikuti bentuk saluran akar. ${ }^{6-8}$ Selain itu, beberapa keuntungan pasak ini dari sisi efesiensi karena tidak memerlukan proses laboratorium sehingga selesai pada satu kali kunjungan, tidak menimbulkan fenomena bayangan abu-abu (grayscale), tahan terhadap trauma, memelihara struktur gigi yang tersisa dan sifat biomekanis yang menyerupai struktur gigi. ${ }^{9,10}$

Laporan kasus ini memaparkan perawatan endodonti dan restoratif yang dilakukan dalam satu kali kunjungan pada dua orang pasien yang mengalami fraktur mahkota pada gigi insisivus maksila yang membutuhkan restorasi estetis segera.

\section{KASUS}

\section{Kasus 1}

Seorang pria usia 28 tahun datang ke Departemen Klinik Konservasi Gigi Fakultas Kedokteran Gigi Universitas Sumatera Utara, dengan keluhan gigi insisivus anterior terasa ngilu dan sakit berdenyut karena fraktur dua minggu yang lalu akibat jatuh saat berolahraga. Pasien mengeluh gigi tersebut sakit terutama ketika minum air dingin. Pada pemeriksaan objektif terlihat gigi insisivus sentralis maksila mengalami fraktur 2/3 mahkota dengan pulpa terbuka. Pada pemeriksaan vitalitas gigi menunjukkan pulpa vital, sedangkan gigi insisivus lateralis maksila terlihat fraktur 2/3 mahkota juga, bahkan hampir $2 \mathrm{~mm}$ di atas gingiva, pulpa terbuka, namun pada pemeriksaan vitalitas menunjukkan gigi masih vital. Pemeriksaan radiografi menunjukkan akar gigi insisivus lateralis maksila memerlukan pasak dan inti untuk menambah retensi restorasi akhirnya (Gambar 1). Kedua gigi tersebut didiagnosa pulpitis irreversible symptomatic.

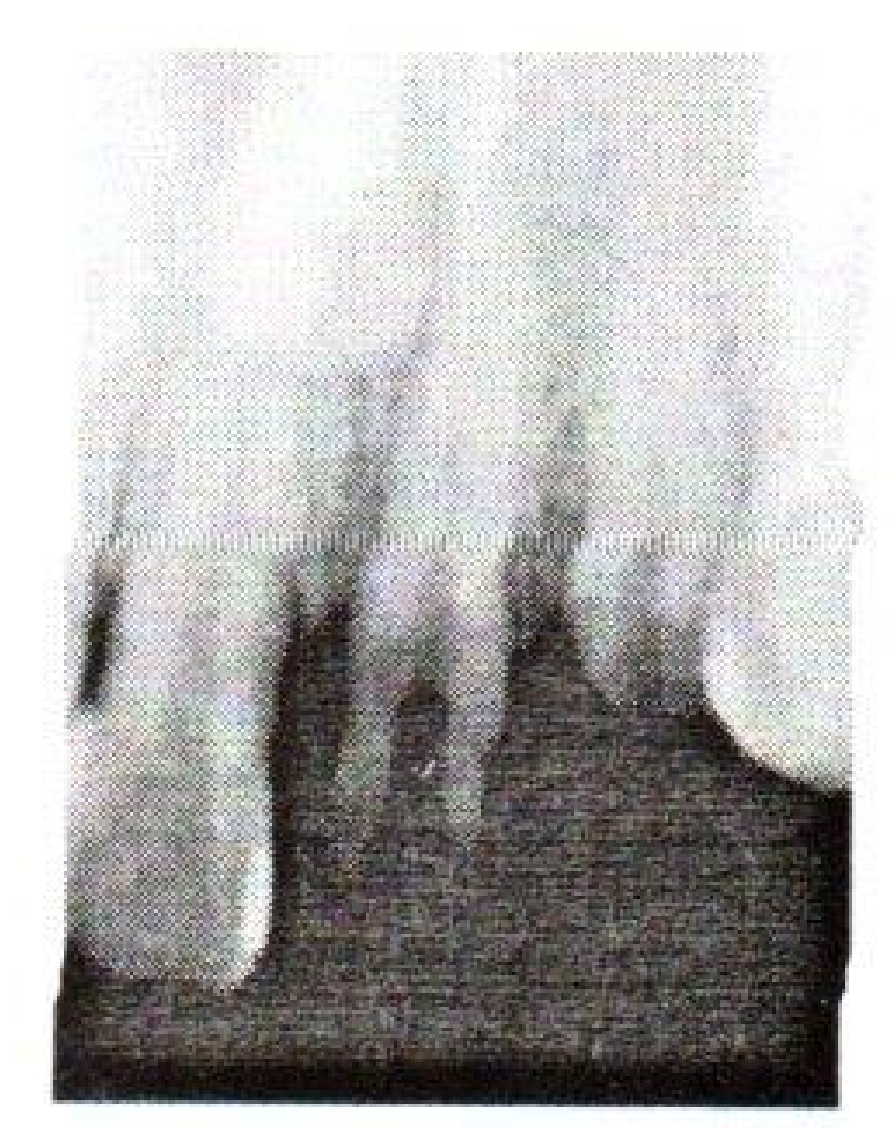

Gambar 1. Pemeriksaan radiografi menunjukkan akar gigi insisivus lateralis maksila memerlukan pasak dan inti untuk menambah retensi resto-rasi akhir

Pada awalnya, rencana perawatan pada kedua gigi tersebut adalah pulpektomi vital dengan restorasi mahkota porselen, tetapi karena pertimbangan biaya dan pasien membutuhkan restorasi segera, hanya gigi insisivus sentalis yang direstorasi dengan mahkota porselen dari gigi insisivus lateralis akan direstorasi dengan pasak customized polyethylene fiber dan resin komposit direk.

\section{Kasus 2}

Seorang pria umur 19 tahun datang ke klinik pribadi dengan keluhan tidak puas dengan restorasi sebelumnya. Dari hasil anamnesis dan pemeriksaan 
klinis dijumpai restorasi resin komposit gigi insisivus lateralis kanan maksila mengalami kerusakan tepi margin (Gambar 2).

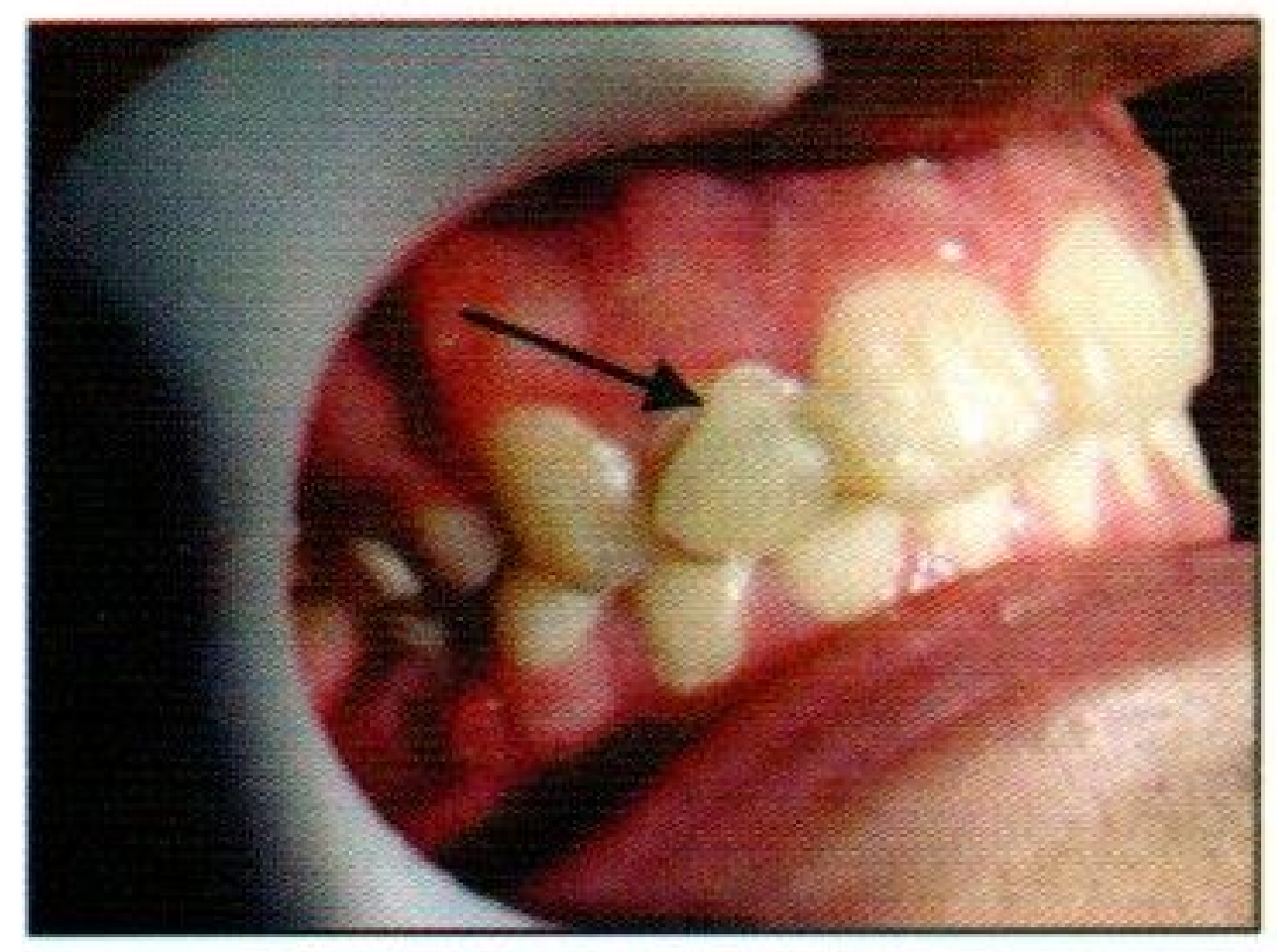

Gambar 2. Pada pemeriksaan klinis dijumpai restorasi resin komposit gigi insisivus lateralis kanan maksila mengalami fraktur tepi marginal

Pemeriksaan radiografi menunjukkan keberadaan pin intrakoronal melintang horizontal pada restorasi resin komposit sebelumnya dan hasil pengisian saluran akar yang tidak sempurna (Gambar 3). Pasien tidak memiliki banyak waktu dan mengharapkan restorasi segera (single visit) untuk memperbaiki estetisnya.

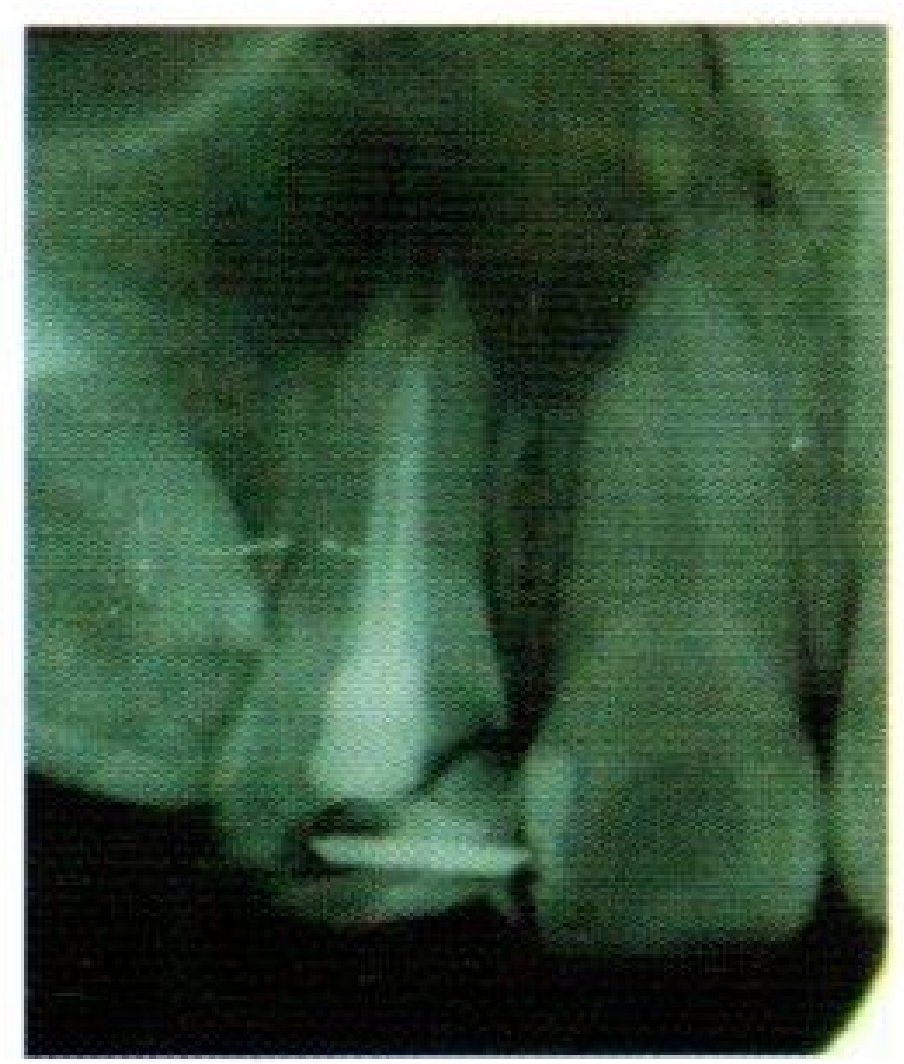

Gambar 3. Gambaran radiografi menunjukkan garis retak antara restorasi resin komposit lama yang diperkuat pin intrakoronal dengan struktur mahkota gigi

\section{PENATALAKSANAAN}

\section{Kasus 1}

Pada kedua insisivus sentralis dan lateralis maksila ini dilakukan pembukaan akses ke dalam ruang pulpa yang kemudian dilakukan pengambilan panjang kerja berdasarkan pengukuran pada gambaran radiografi, yaitu $21 \mathrm{~mm}$ untuk insisivus sentralis maksila dan $14 \mathrm{~mm}$ untuk insisivus lateralis maksila. Saluran akar dipreparasi dengan teknik step back menggunakan File-K (FKG Dentaire, Swiss) dengan terus melakukan irigasi dengan larutan sodium hipoklorit $2,5 \%$. Setelah itu, dilakukan obturasi menggunakan sealer (Endomethasone, Septodont) dan gutaperca (Inline, Feathered) dengan teknik kondensasi lateral dan vertikal lalu ditutup dengan semen zink fosfat. Pada insisivus sentralis dipersiapkan built up komposit resin untuk preparasi full crown porcelain fused metal sedangkan insisivus lateralis maksila dipersiapkan untuk pemasangan pasak inti dari pita polyethylene fiber (Gambar 4).

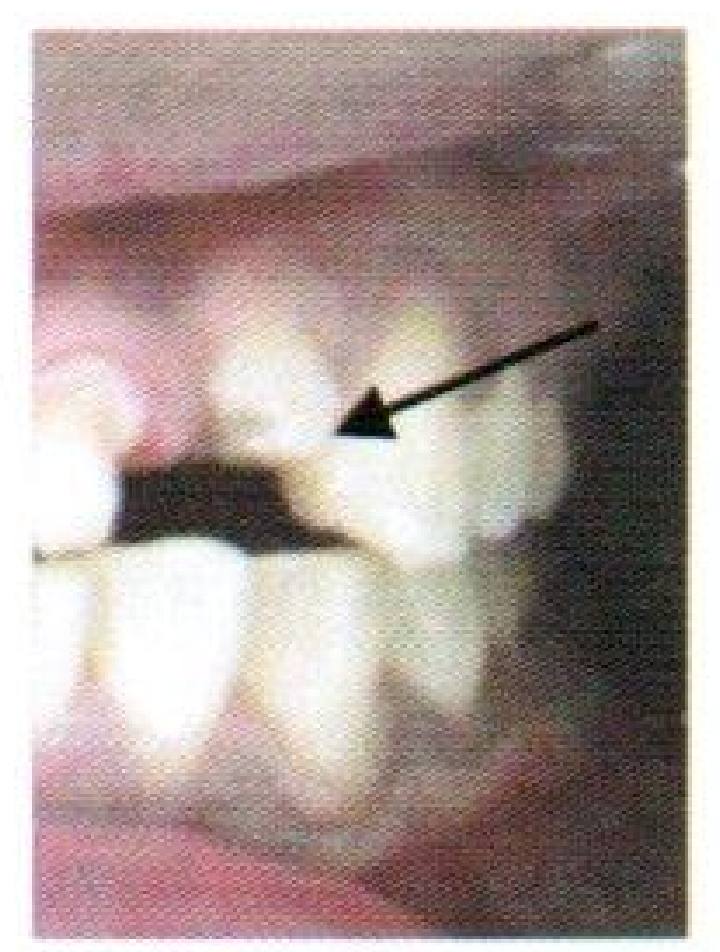

Gambar 4. Insisivus lateralis maksila dipersiapkan untuk pemasangan pasak fiber dari pita polyethylene

Setelah dilakukan obturasi pada saluran akar gigi insisivus lateralis, kemudian dilakukan pembuangan gutaperca dengan menggunakan rimer-peeso (FKG Dentaire,Swiss) gutaperca bagian korona dibuang kurang lebih sebanyak $1 / 2$ bagian saluran akar (Gambar 5).

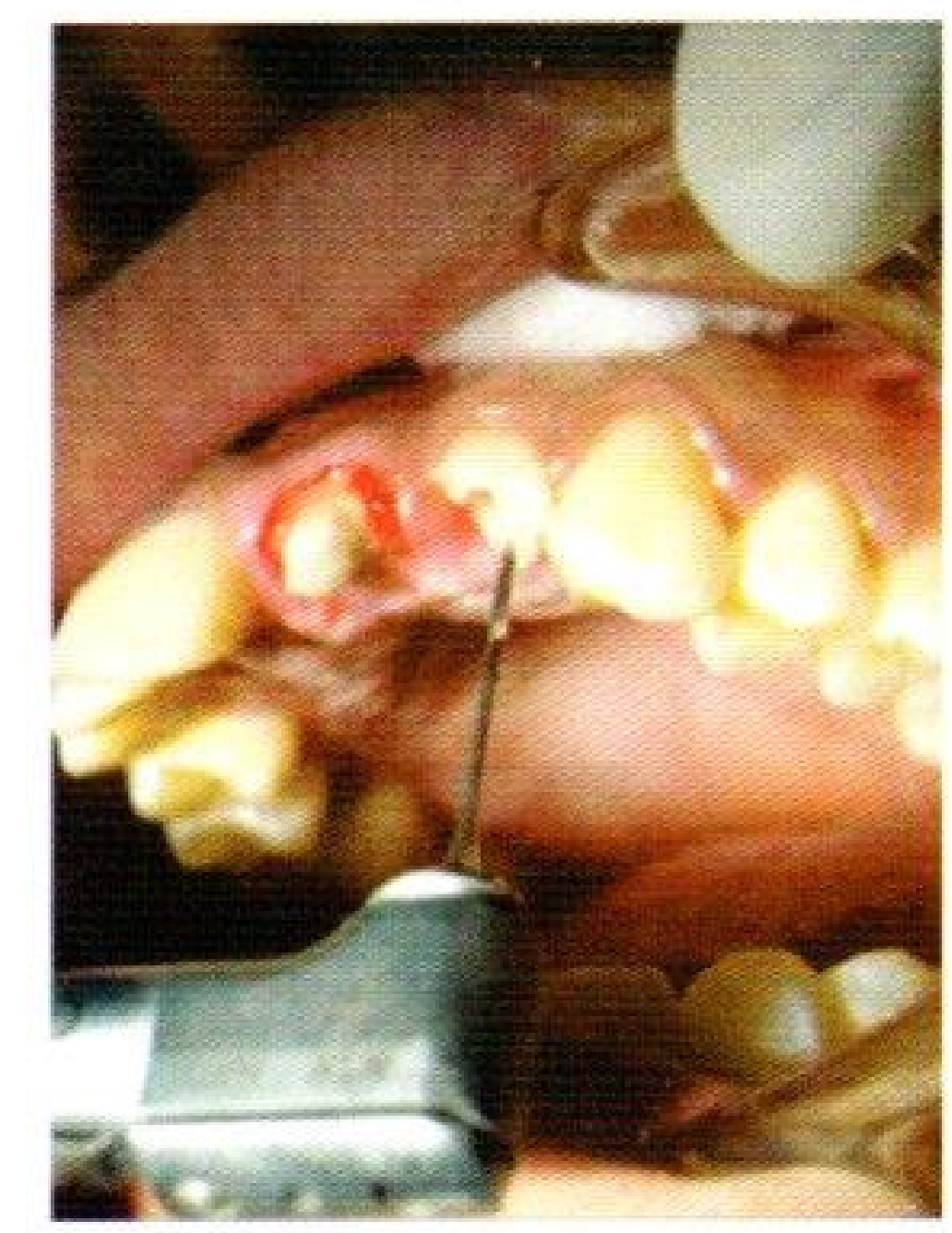

Gambar 5. Setelah dilakukan obturasi pada saluran akar gigi insisivus lateralis, dilakukan pembuangan gutaperca dengan menggunakan peaso rimerpeeso untuk persiapan ruang pasak

Kemudian saluran akar dibersihkan dengan larutan hipoklorit 2,5\% setelah itu, dikeringkan dengan kertas penyerap (Inline, Absorbent). Pada enamel diaplikasikan etsa selama 15 detik menggunakan phosphoric acid $35 \%$ (Scotchbond $^{\mathrm{TM}} 3 \mathrm{M}$ ESPE), dibilas dengan air kemudian saluran akar dikeringkan dengan mempertahankan kelembapan. Dentin bonding (AdperTM Single Bond 2, 3M ESPE) diletakkan pada seluruh permukaan dentin yang tersisa selama 10 detik dan dipolimerisasi menggunakan suatu LED curing light (Heraus Kulzer). Semen luting resin (RelyX ${ }^{\mathrm{TM}} \mathrm{U} 100,3 \mathrm{M}$ ESPE) disiapkan di atas paper slab dengan perbandingan 1:1, kemudian diaduk dan dimasukkan kedalam saluran akar dengan menggunakan lentulo spiral 
(FKG Dentaire,Swiss). Sebelumnya telah dilakukan estimasi panjang saluran akar gigi incisivus lateralis dengan menggunakan benang gigi, dan pita polyethylene fiber (Ribbond ${ }^{\circledR}$ THM, Seattle, WA,USA) dengan lebar $3 \mathrm{~mm}$ diukur dan digunting sepanjang benang gigi dengan menggunakan gunting khusus (Gambar 6). Hal ini dilakukan agar dapat menghindari kontaminasi pita Polyethylene fiber dengan serbuk dari sarung tangan yang akan mempengaruhi ikatan adhesif pita dengan semen luting resin

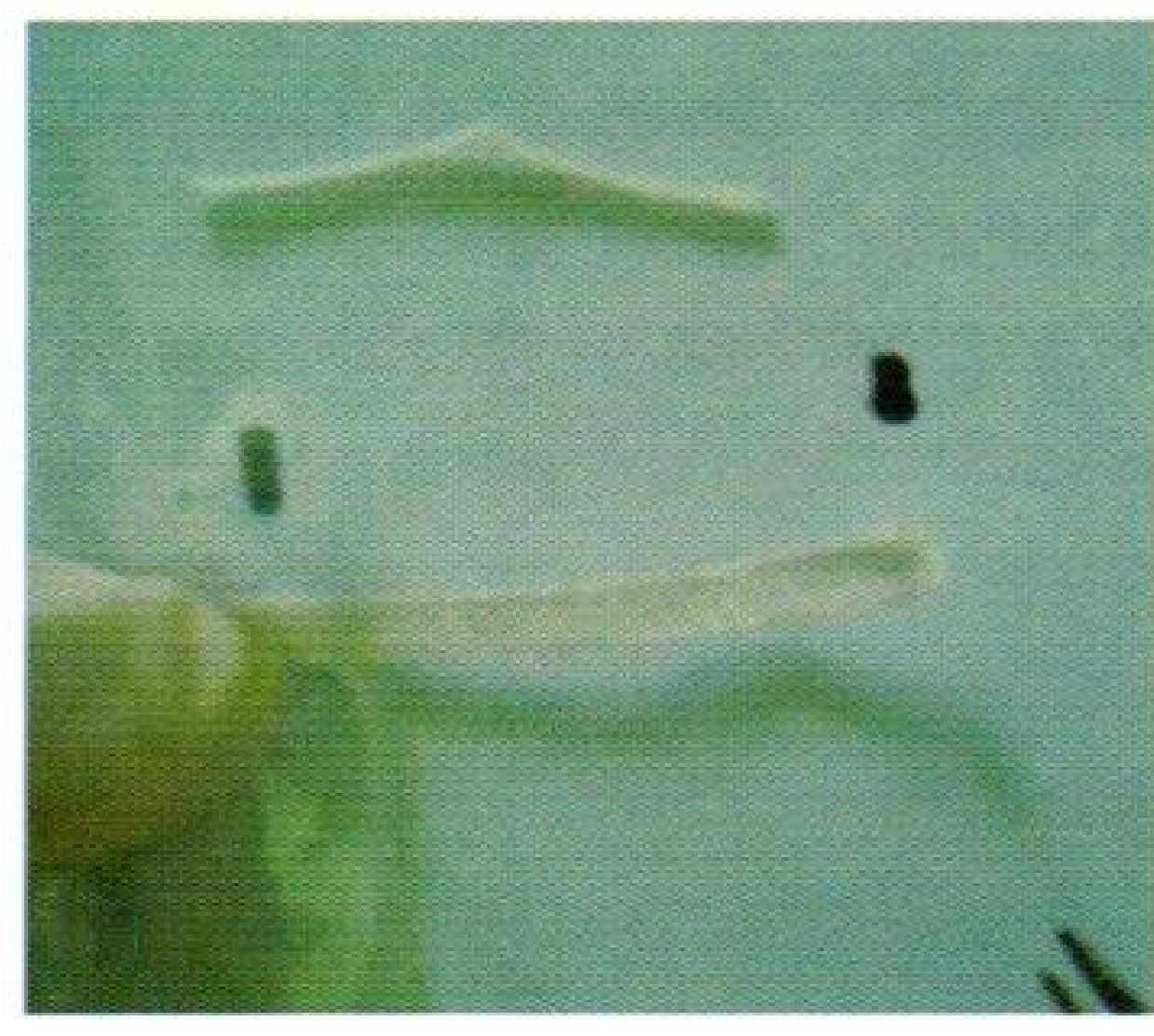

Gambar 6. Pemotongan pita polyethylene fiber-reinforcement (Ribbond ${ }^{(R)}$ THM, Seattle, WA,USA) sesuai pengukuran estimasi panjang saluran akar gigi dengan menggunakan benang gigi

Kemudian permukaan pita polyethylene fiber dibasahi dengan bahan unfilled resin (Wetting Resin, Ultradent) lalu dimasukkan ke dalam saluran akar yang sudah tergenang dengan semen luting resin dengan cara menekan instumen pemampat yang telah ditumpulkan bagian ujungnya, sehingga pita polyethylene fiber tersebut terlipat menjadi dua bagian di dalam saluran akar. Kemudian ujung yang berlebih dipolimerisasi dengan penyinaran selama 20 detik. Resin komposit micro hybrid (Filtex Z250, 3M ESPE) diaplikasikan pada permukaan gigi dengan teknik inkremental sehingga membentuk mahkota klinis dari gigi insisivus lateralis (Gambar 7).

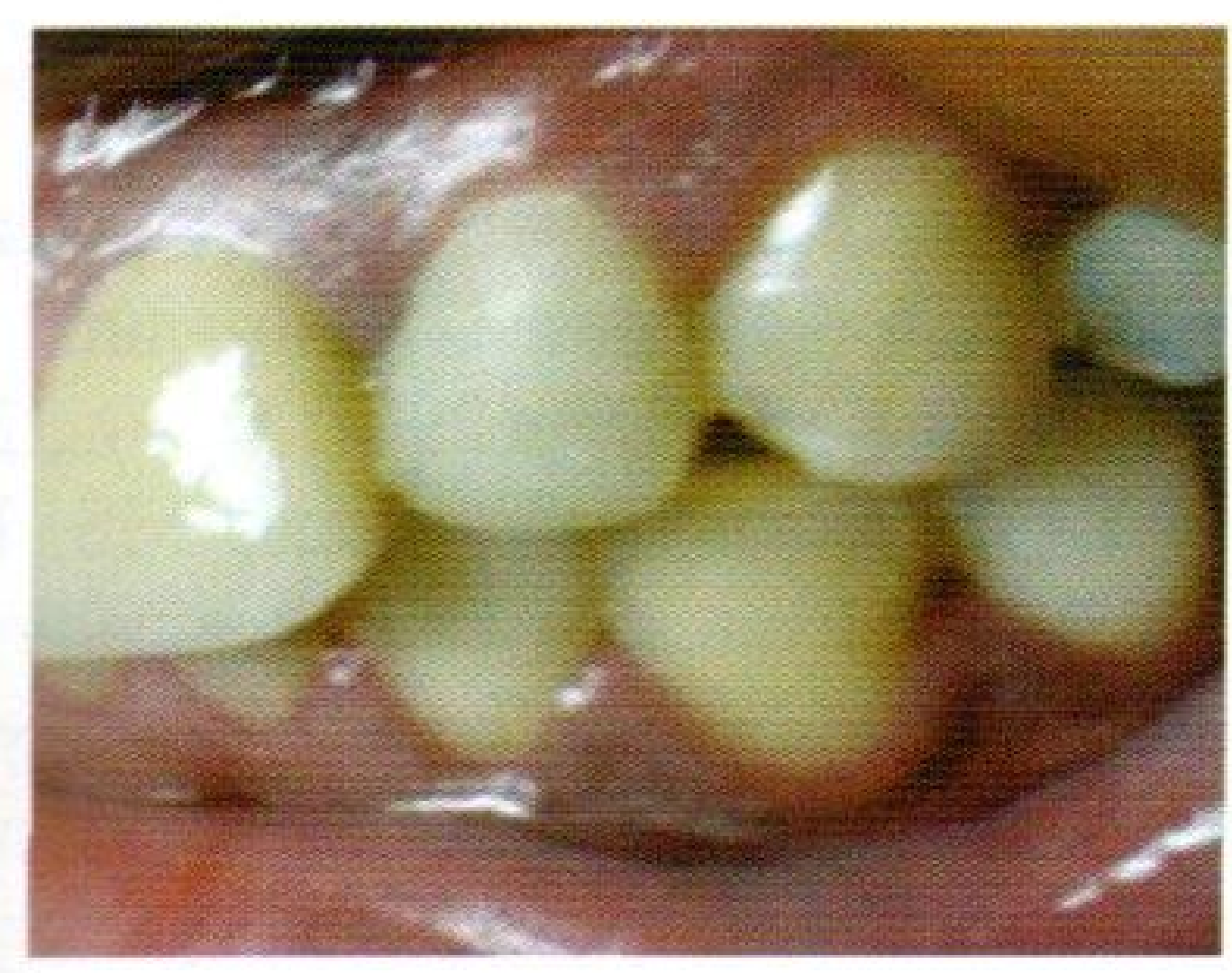

7. Pembentukan mahkota klinis pada gigi insisivus lateralis maksila menggunakan resin komposit dengan tehnik incremental

Tahap terakhir dilakukan finishing dan polishing tengan menggunakan Soflex (3M ESPE). Pada 6 berikutnya pasien diminta datang kembali untuk kontrol evaluasi, restorasi resin komposit masih dalam keadaan baik. Pada Gambar 8 terlihat gambaran radiografi dari pasak yang terbuat dari pita polyethylene fiber.

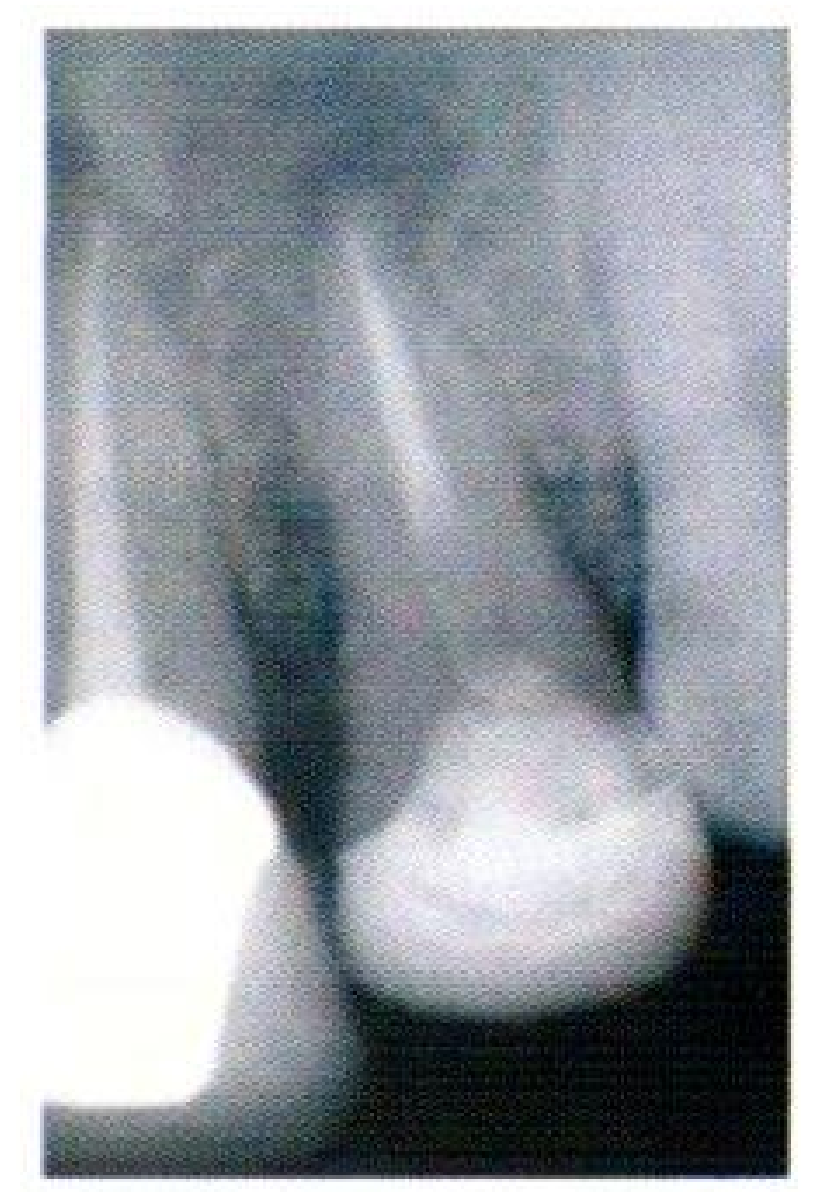

Gambar 8. Gambaran radiografi pada kontrol 6 bulan menunjukkan restorasi resin komposit masih dalam keadaan baik namun pasak pita polyethylene fiber tidak opak seperti gutaperca

\section{Kasus 2}

Resin komposit pada restorasi sebelumnya, termasuk pin didalamnya dibuang dengan menggunakan bur intan. Bahan obturasi lama dibongkar dengan Hendstrom file (FKG Dentaire, Swiss) dan kemudian dilakukan perawatan endodonti ulang satu kali kunjungan. Setelah prosedur obturasi selesai, guta perca bagian koronal dibuang dengan rimer-peeso dengan tetap meninggalkan bahan obturasi di daerah apikal untuk mendapatkan penutupan yang lebih baik. Struktur mahkota yang tersisa dibuat bevel mengelillingi margin enamel dentin dari tepi fraktur menggunakan bur intan. Bahan polyethylene fiber disiapkan dan dimasukkan dengan melipat bahan tersebut seperti teknik pada kasus 1 . Komposit resin micro hybrid (Filtex Z250, 3M ESPE) diaplikasikan dengan cara teknik inkremental sebagai restorasi direk veneer untuk membentuk restorasi akhir (Gambar 9).

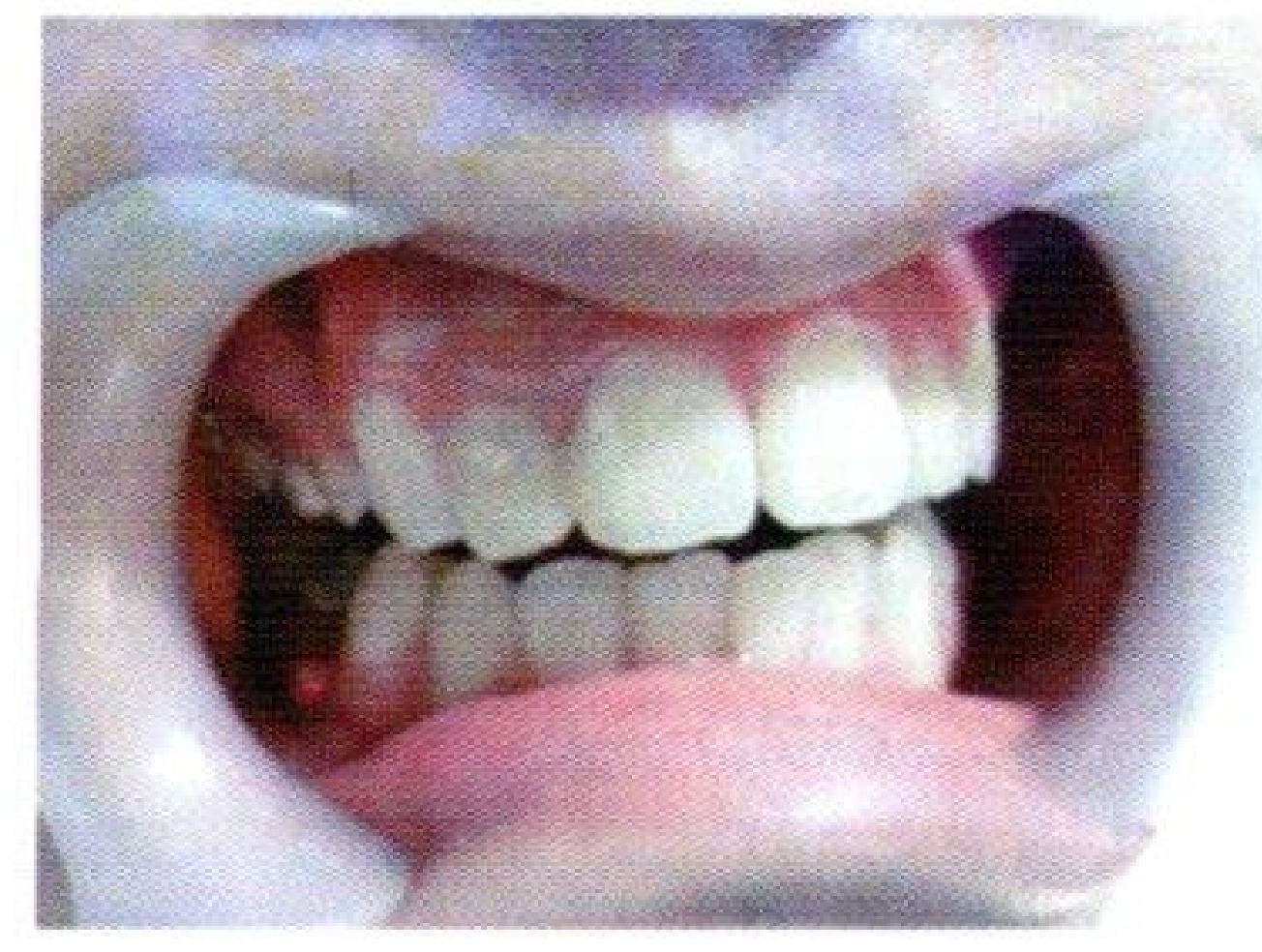

Gambar 9. Komposit resin micro hybrid (Filtex Z250, 3M ESPE) diaplikasikan dengan cara teknik inkremental sebagai restorasi direk veneer untuk membentuk restorasi akhir pada gigi insisivus lateralis kanan maksila 


\section{PEMBAHASAN}

Pasak yang ideal harus dapat menggantikan struktur gigi yang hilang, biokompatibel, memberikan retensi yang cukup terhadap gigi dan memiliki modulus elastisiti yang menyerupai dentin. Pasak fiber memiliki seluruh sifat tersebut dan sebagai tambahan pasak fiber mudah dikeluarkan dari saluran akar jika diperlukan perawatan endodonti ulang. ${ }^{8}$

Aspek estetis dan mekanis akan menjadi pertimbangan apabila terjadi fraktur pada restorasi mahkota gigi anterior. Dalam dua laporan kasus ini, digunakan pasak yang terbuat dari pita customized polyethelene fiber untuk memperkuat pasak dan inti secara struktural dalam satu kali kunjungan. Bahan ini berbentuk anyaman yang sangat kuat terdiri atas bahan ultra high polyethylene fiber yang dapat menghasilkan retensi adhesif, efektif menyalurkan tekanan melalui anyaman, mudah dibentuk dengan mengikuti bentuk morfologi akar dan warna yang estetis., ${ }^{2,8}$

Pasak yang dibuat dari polyethylene fiber mempunyai kekuatan yang lebih baik daripada pasak metal tuang karena pada sistem pasak polyethylene fiber digunakan semen luting resin yang berbahan dasar sama sehingga semen resin mudah meresap ke jalinan anyaman polyethylene fiber dengan demikian tercipta kontak yang rapat dengan bentuk saluran akar dan terjadi ikatan adhesif antara semen resin dengan pasak. ${ }^{9,11}$

Penggunaan unfilled resin pada bahan polyethylene fiber untuk membasahi permukaan bahan tersebut dianjurkan agar bahan tersebut dapat berikatan dengan semen resin yang akan masuk ke dalam celah anyaman pita polyethylene fiber. ${ }^{8} \mathrm{Be}-$ berapa literatur ada yang menyarankan penggunaan flowable komposit sebagai pengganti unfilled resin. $^{7}$

Pada laporan kasus ini dual cure resin cement dimasukkan dengan menggunakan lentulo spiral. Penggunaan needle-tube syringe memudahkan bahan luting semen resin mengalir ke dalam saluran akar. Teknik ini dapat mengurangi kemungkinan terperangkapnya gelembung udara dan memastikan adaptasi bahan resin ke ruang preparasi pasak lebih optimal. Namun, untuk melakukan evaluasi kepadatan bahan di dalam saluran akar pada saat evaluasi, sedikit sulit karena bahan semen luting resin dan pita polyethelene fiber tidak memiliki gambaran radiopak. ${ }^{3,9}$ Oleh karena itu, gambaran radiografi pasak customized polyethelene fiber ini tidak begitu jelas.

Preparasi bevel melingkari gigi di atas servikal sebanyak 1-2 mm sebagai efek ferul perlu diperhati- kan untuk meningkatkan retensi dan resistensi restorasi. Selain itu, efek ferul berfungsi sebagai anti rotasi pasak dan mencegah terjadinya fraktur akar. Beberapa penelitian menunjukkan bahwa restorasi pasak polyethylene fiber dengan ferul memiliki ketahanan fraktur yang lebih baik dibandingkan tanpa ferul. Walaupun fraktur pada akar tetap dapat terjadi namun pola fraktur berada pada bagian koronal sehingga restorasi masih dapat diperbaiki (repairable). ${ }^{2,3,10,11}$

Kontak permukaan dinding saluran akar dengan bahan pasak adhesif merupakan hal yang penting dalam keberhasilan sistem pasak adhesif. Penggunaan larutan irigasi, bahan medikamen dan bahan pengisian seperti sealer dan guta perca dapat mempengaruhi komposisi kimia permukaan dentin yang akan berikatan dengan bahan sistem adhesif. ${ }^{10} \mathrm{Se}-$ lain itu, smear layer yang terbentuk akibat preparasi dentin juga dapat mempengaruhi perlekatan adhesif. ${ }^{2.8}$ Pada kasus ini digunakan jenis sistem adhesif total etsa agar dapat menghilangkan seluruh smear layer yang dapat menghalangi penetrasi bonding dentin. Beberapa laporan kasus merekomendasikan penggunaan sealer berbasis resin untuk sementasi pasak fiber. ${ }^{27,10}$

Sebagai kesimpulan, restorasi pasak pita polyetherlene fiber resin reinforced dapat dilakukan untuk kasus trauma seperti fraktur mahkota. Walaupun pemasangan restorasi indirek dianjurkan pada kasus pasca perawatan endodonti, penggunaan restorasi resin komposit direk veneer dengan pasak dan inti yang diperkuat pita polyethelene fiber resin reinforced menjadi alternatif perawatan pada pasien dengan kasus trauma yang membutuhkan restorasi estetis segera.

\section{Daftar Pustaka}

1. Cheung W. A review of the management of endodontically treated teeth: post, core and the final restoration. JADA 2005; 136: 611-19.

2. Terry AD, Triolo PT Jr, Swift EJ Jr. Fabrication of direct fiber-reinforced posts: a structural design concept. J Esthet Restor Dent 2001; 13(4): 228-40.

3. Piovesan EM, Demarco FF, Cenci MS, PereiraCenci T. Survival rates of endodontically treated teeth restored with fiber-reinforced custom posts and cores: a 97-month study. Int J Prosthodont 2007; 20(6): 633-9.

4. Torabi K, Fattahi F. Fracture resistance of endodontically treated teeth restored by different FRC post: an in vitro study. Indian J Dent Res 2009; 20(3): 282-7.

5. Nishimura Y, Tsubota Y, Fukushima S. Influence of cyclic loading on fiber post and composite resin core. Dental Material J 2008; 27(3): 356-61.

6. Garoushi S, Vallittu PK, Lassila LVJ. Continuous 
and short fiber reinforced composite in root postcore system of severely damaged incisors. J Oper Dent 2009; 3: 36-41.

7. Deliperi S, Bardwell DN, Colana C. Reconstruction of devital teeth using direct fiber-reinforced composite resins: a case report. J Adhes Dent 2005; 7(2): 165-71.

8. Belli S, Gurcan E. Biomechanical properties and clinical use of a polyethylene fibre post-core material. In: Ferrari M, Breschi L, Grandini S. Fiber posts and edodontically treated teeth: a compendium of scientific and clinical perspectives. $1^{\text {st }}$ ed.,
Wendywood: Modern Dentistry Media, 2008: 39-50.

9. Catagay B, Osman TH, Mehmet Y. Restoration of crown fractures with a fiber post, polyethylene fiber and composite resin: a combined restorative technique with two case reports. Rev Clin Pesq Odontol 2009; 5(1): 73-7.

10. Gluskin AH, Ahmad I, Herrero DB. The aesthetic post and core unifying radicular form and sructure. Pract Proced Aesthet Dent 2002; 14(4): 313-21.

11. Ganesh M, Tandon S. Versatility of ribbon in contemporary dental practice. Trends Biomater 2006; 20(1): 53-8 